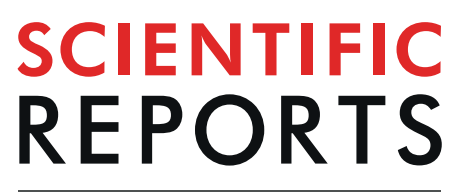

natureresearch

\title{
OPEN The Vitamin D status is associated with serum C-reactive protein and adhesion molecules in patients with renal cell carcinoma
}

\author{
Shen $\mathrm{Xu}^{1}$, Jin Song ${ }^{2}$, Zhi-Hui Zhang ${ }^{2}$, Lin $\mathrm{Fu}^{3,4}$, Lan Gao ${ }^{3,4}$, Dong-Dong Xie ${ }^{2}$, De-Xin $\mathrm{Yu}^{2}$, \\ De-Xiang $X u \mathbb{1}^{3,4^{*}}$ \& Guo-Ping Sun ${ }^{1 *}$
}

Low vitamin $D$ status is associated with an increased risk of renal cell carcinoma (RCC). This study investigated the association of vitamin D status with serum C-reactive protein (CRP) and adhesion molecules among RCC patients. Fifty newly diagnosed RCC patients and 100 age- and sex-matched controls were recruited. As expected, serum $25(\mathrm{OH}) \mathrm{D}$ level was lower in RCC patients than in controls. By contrast, serum levels of CRP, an inflammatory molecule, and ICAM, LAMA4 and EPCAM, three adhesion molecules, were higher in RCC patients than in controls. All RCC patients were divided into two groups: H-VitD $(>20 \mathrm{ng} / \mathrm{ml})$ or L-VitD $(<20 \mathrm{ng} / \mathrm{ml})$. Interestingly, the levels of serum CRP and all adhesion molecules were higher in RCC patients with L-VitD than those with H-VitD. Nuclear vitamin D receptor (VDR) was downregulated and nuclear factor kappa $B(N F-\kappa B)$ was activated in cancerous tissues. The in vitro experiments found that VitD3 suppressed NF- $\kappa$ B activation and adhesion molecules in RCC cells. Moreover, VitD3 suppressed NF- $\kappa B$ through reinforcing physical interaction between VDR and NF- $K B$ p 65 subunit in RCC cells. These results provide a mechanistic explanation for the association among low vitamin $D$ status, local inflammation and increased expression of adhesion molecules among RCC patients.

Renal cell carcinoma (RCC) is common malignant tumor in urinary tract, among which clear cell RCC (ccRCC) is the most common subtype ${ }^{1,2}$. Increasing data suggest that hypertension, obesity, long-term sodium intake, high glycemic index diet, and cigarette smoking are the major risk factors for $\mathrm{RCC}^{3-7}$. Numerous studies have demonstrated that inflammatory molecules, such as C-reactive protein (CRP), promote RCC progression ${ }^{8-10}$. Other studies have indicated that inflammatory cytokines, such as tumor necrosis factor alpha (TNF- $\alpha$ ), lead to a poor prognosis ${ }^{11}$. On the other hand, adhesion molecules, such as intercellular adhesion molecule (ICAM)-1, vascular cell adhesion molecule (VCAM)-1, melanoma cell adhesion molecule (MCAM), and epithelial cell adhesion molecule (EpCAM), are involved in invasion and migration of malignant tumors ${ }^{12-15}$. In addition, MCAM and EpCAM are prognostic molecular markers in patients with malignant tumors ${ }^{16-24}$. Nevertheless, which factors up-regulate inflammatory molecules and adhesion molecules in cancer cells have not yet been elucidated.

Vitamin D is a secosteroid hormone for calcium and phosphorus metabolism ${ }^{25}$. Several recent studies demonstrate that vitamin D regulates cell proliferation and differentiation, immune response. In addition, vitamin $\mathrm{D}$ has anti-cancer, anti-inflammatory and anti-oxidative effects ${ }^{26-30}$. Vitamin D deficiency (VDD) is defined as lower than $20 \mathrm{ng} / \mathrm{ml}$ of $25(\mathrm{OH}) \mathrm{D}^{31,32}$. Numerous epidemiological reports demonstrated that VDD was positively linked with cancer incidence and a poor clinical prognosis ${ }^{33-36}$. Recently, a large epidemiological investigation showed that VDD was associated with an elevated risk of RCC in men and women ${ }^{37}$. Vitamin D3 (VitD3) is metabolized to $25(\mathrm{OH}) \mathrm{D} 3$ by cytochrome P450 (CYP)2R1 in the liver and then metabolized into 1,25(OH)2D3 by CYP27B1 in the kidney ${ }^{38}$. The effects of vitamin D3 are mediated by vitamin D receptor (VDR ${ }^{39}$. Indeed, CYP27B1 and

\footnotetext{
${ }^{1}$ Department of Oncology, First Affiliated Hospital, Anhui Medical University, Hefei, 230022, China. ${ }^{2}$ Department of Urology, Second Affiliated Hospital, Anhui Medical University, Hefei, 230601, China. ${ }^{3}$ Department of Toxicology, School of Public Health, Anhui Medical University, Hefei, 230032, China. ${ }^{4}$ Key Laboratory of Environmental Toxicology of Anhui Higher Education Institutes, Anhui Medical University, Hefei, 230032, China. *email: xudex@126.com; sungp@ahmu.edu.cn
} 
VDR are highly expressed in human kidney ${ }^{40}$. Therefore, it is especially interesting whether there is an association between VDD and increased inflammatory and adhesion molecules among RCC patients.

The purpose of this study was to analyze the link among serum $25(\mathrm{OH}) \mathrm{D}$, local inflammatory signaling and increased expression of adhesion molecules among RCC patients. We found that serum 25(OH)D level were lower in RCC patients than in controls. By contrary, the levels of serum CRP and several adhesion molecules were elevated in RCC patients. The present study suggests a link among low vitamin D status, local inflammation and increased expression of adhesion molecules in RCC patients.

\section{Materials and Methods}

Study participants. Total 50 newly diagnosed RCC patients, whose ages ranged from 40 to 75 years old, were recruited as cases. All cases were diagnosed as RCC patients for the first time between January 2013 and December 2014. RCC was confirmed by histopathology. Total 100 control subjects were from physical examination at the Second Affiliated Hospital of the Anhui Medical University. Two control subjects were matched with one RCC case regarding age (within 2 years), sex and season of blood sample. Individuals with a history of cystic nephropathy, tuberous sclerosis, and severe kidney disease were excluded from this study. Patients were staged using the AJCC TNM system ${ }^{41}$. Tumors were graded according to the Fuhrman system ${ }^{42}$. All slides were examined by two pathologists to ensure diagnostic correction. Serum collection and research procedure obtained approval from the ethics committee of Anhui Medical University. Oral and written consents were obtained from all subjects. All participants signed informed consent forms and were told they could quit at any time. All methods, including methods mentioned below, followed the relevant guidelines and regulations.

Reagents. Antibodies against MCAM, LAMA4, EpCAM and VDR were from Cell Signaling Technology (Beverley, MA). Antibodies against NF- $\kappa$ B p65, p-I $\kappa$ B and $\beta$-actin were from Santa Cruz Biotechnologies (Santa Cruz, CA). Chemiluminescence detection kit was from Pierce Biotechnology (Rockford, IL). All other reagents were purchased from Sigma Chemical Co. (St. Louis, MO) if not otherwise stated.

Biochemical measurement. Venous blood was drawn in the morning with more than 8 hours fasting. Serum creatinine, uric acid, urea nitrogen, calcium and serum phosphorus were measured with automatic biochemical analyzer (KHBZY-1200).

Radioimmunoassay (RIA). Serum 25(OH)D concentration was measured by RIA using a commercial kit (DiaSorin Inc, Stillwater, MN, USA) as our previous study ${ }^{43}$. Serum 25(OH)D concentrations were expressed as $\mathrm{ng} / \mathrm{ml}$. Less than $20 \mathrm{ng} / \mathrm{mL}$ for $25(\mathrm{OH}) \mathrm{D}$ level was defined as VDD.

Cell culture and treatments. ACHN cells and 786-o cells are two types of renal cell cancer cell lines that are from the cell bank of the Chinese Academy of Sciences (Shanghai). The cells were inoculated in a $10 \mathrm{~cm}$ culture dish and cultured in $5 \%$ carbon dioxide at $37^{\circ} \mathrm{C}$ with $100 \mathrm{U} / \mathrm{ml}$ penicillin-streptomycin and $10 \%$ serum MEM/EBSS (HyClone, for ACHN) or RPMI Medium Modified (HyClone, for 786-O) medium. When the cells grew to 80\% full, the mediums were replaced by serum-free mediums. $1,25(\mathrm{OH}) \mathrm{D} 2$ was pretreated for 24 hours before LPS was added. Supernatant was collected after 6 hours for ELISA. Cells were collected for Western blot and Co-IP analysis.

Co-immunoprecipitation (Co-IP). The collected cells were washed twice with PBS and then lysed for $20 \mathrm{~min}$ with $400 \mu \mathrm{l}$ lysis buffer to obtain total protein. The protein was quantified by BCA Protein Quantitation $\mathrm{Kit}$, and $1000 \mu \mathrm{g}$ Protein was diluted to $1.2 \mathrm{ml}$. About $20 \mu \mathrm{l}$ protein A/G-agarose was added for incubation for $2 \mathrm{~h}$, and supernatant was taken. The supernatant was added with $2 \mu \mathrm{g}$ anti-VDR antibody, and after $3 \mathrm{~h}$ incubation, 40 $\mu \mathrm{l}$ protein A/G-agarose was added for incubation. After $10 \mathrm{~h}$, agarose was collected, washed, and boiled for $10 \mathrm{~min}$ with $60 \mu \mathrm{l}$ loading buffer. Supernatant was collected for immunoblots using VDR and NF- $\kappa$ B p 65 antibodies.

Enzyme-linked immunosorbent assay (ELISA) Measurements of CRP and adhesion molecules. CRP and adhesion molecules (ICAM-1, VCAM-1, MCAM, LAMA4 and EpCAM) were measured using ELISA kits (R\&D Systems, Abingdon, Oxon, UK) according to the manufacturer's protocol.

Immunohistochemistry (IHC). The methods of IHC referred to our previous study with minor modification $^{43}$. Briefly, human RCC specimens were fixed in $4 \%$ formalin and embedded in paraffin according to the standard procedure. For IHC, paraffin-embedded renal sections were deparaffinized and rehydrated in a graded ethanol series. After antigen retrieval and quenching of endogenous peroxidase, sections were incubated with specific antibodies (MCAM and EpCAM) at $4{ }^{\circ} \mathrm{C}$ overnight. The color reaction was developed with HRP-linked polymer detection system and counterstaining with hematoxylin. Tissue sample collection and research procedure obtained approval from the ethics committee of Anhui Medical University.

Western blot. Eight specimens were randomly selected from cancer patients, whose mean level of serum $25(\mathrm{OH})$ $\mathrm{D}$ was $20.73 \mathrm{ng} / \mathrm{ml}$. Tissue lysate and protein extraction referred to the previous study ${ }^{43}$. For Western blot, $20 \mu \mathrm{g}$ of protein in loading buffer was subjected to electrophoresis in $12.5 \%$ SDS-PAGE for $3 \mathrm{~h}$. The gel was transferred electrophoretically onto a PVDF membrane (Immobilon-P; Millipore powdered milk in Dulbecco's PBS). The membranes were blocked by nonfat milk and then incubated for $2 \mathrm{~h}$ using following antibodies: either VDR or p-IkB or p-p65. For total proteins, $\beta$-actin was used as a loading control. For nuclear protein, lamin $\mathrm{A} / \mathrm{C}$ was used as a loading control. After washed in Dulbecco's PBS-T for four times and PBS once, the membrane was incubated with goat anti-rabbit or horse anti-goat IgG antibody for $2 \mathrm{~h}$. The membrane was then washed 4 times in Dulbecco's PBS-T for 10 min and PBS for $10 \mathrm{~min}$, followed by signal development using an enhanced chemiluminescence (ECL) detection kit. 


\begin{tabular}{|l|c|c|c|}
\hline & Control $(\mathbf{n}=\mathbf{1 0 0})$ & Case $(\mathbf{n}=\mathbf{5 0})$ & P value \\
\hline Mean age $($ years), mean $(\mathrm{SD})$ & $56.55(11.57)$ & $56.88(11.91)$ & 0.871 \\
\hline Sex, male $(\%)$ & $73(73)$ & $36(72)$ & 0.897 \\
\hline BMI $\left(\mathrm{kg} / \mathrm{m}^{2}\right)$ & $21.18(2.57)$ & $24.26(3.24)$ & $<0.001$ \\
\hline Serum creatinine $(\mu \mathrm{mol} / \mathrm{L})$ & $80.09(18.12)$ & $85.72(31.89)$ & 0.706 \\
\hline Serum urea nitrogen $(\mathrm{mmol} / \mathrm{L})$ & $5.03(1.00)$ & $5.81(1.53)$ & $<0.001$ \\
\hline Serum uric acid $(\mathrm{mmol} / \mathrm{L})$ & $375.35(96.70)$ & $381.11(97.16)$ & 0.704 \\
\hline Serum calcium $(\mathrm{mmol} / \mathrm{L})$ & $2.27(0.13)$ & $2.21(0.09)$ & 0.039 \\
\hline Serum phosphorus $(\mathrm{mmol} / \mathrm{L})$ & $1.15(0.24)$ & $1.18(0.26)$ & 0.737 \\
\hline
\end{tabular}

Table 1. The demographic and serum biochemical parameters between cases and controls

\begin{tabular}{|l|l|}
\hline \multicolumn{2}{|l|}{ Case (n=50) } \\
\hline Fuhrman Grades (\%) & $2(4)$ \\
\hline Fuhrman I & $28(56)$ \\
\hline Fuhrman II & $13(26)$ \\
\hline Fuhrman III & $7(14)$ \\
\hline Fuhrman IV & $12(24)$ \\
\hline AJCC TNM Stages (\%) & $22(44)$ \\
\hline T1a & $9(18)$ \\
\hline T1b & $7(14)$ \\
\hline T2 &
\end{tabular}

Table 2. Fuhrman Grades and AJCC TNM Stages

A

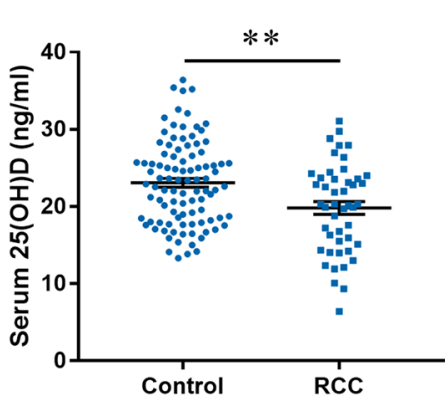

B

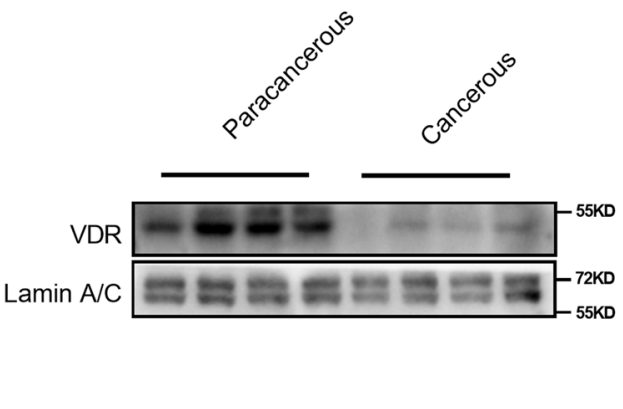

C

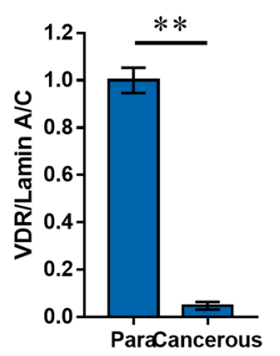

Figure 1. Serum 25(OH)D level and VDR distribution among RCC patients. (A) Serum 25(OH)D level in RCC patients and controls. Serum $25(\mathrm{OH}) \mathrm{D}$ was measured by RIA. All data were expressed as means \pm S.E.M. $* * \mathrm{P}<0.01$. ( $\mathrm{N}=50$ for RCC patients; $\mathrm{N}=100$ for control subjects). (B,C) Nuclear VDR level was measured using Western blot. (B) A representative gel for VDR (upper panel) and Lamin A/C (lower panel) was shown. (C) VDR/Lamin A/C. The grouping of blots cropped from different gels of same samples. All data were expressed as means \pm S.E.M. $(\mathrm{N}=8)$. $* * P<0.01$.

Statistical analysis. The difference between two independent groups was compared using two student $t$ test or the Mann-Whitney U-test. Comparative analyses of categorical variables were carried out by the chi-square test. The link between $25(\mathrm{OH}) \mathrm{D}$ and adhesion molecules was analyzed using linear correlation. A $P$ value of less than 0.05 was considered statistically significant.

\section{Results}

Demographic characteristics and grades of renal cell carcinoma. The demographic characteristics are shown in Table 1. As expected, no difference on mean age and sex composition was observed between RCC patients and controls. There was no difference on serum creatinine, uric acid and phosphorus levels between two groups. BMI index and serum urea nitrogen were higher in RCC patients than those of controls (Table 1). By contrary, the levels of serum calcium were lower in RCC patients than those of controls (Table 1). The number of cases at different stages and grades was then analyzed. As shown in Table 2, 60\% (30/50) of RCC patients belonged to $\mathrm{G} 1 / 2$ and $40 \%(20 / 50)$ belonged to G3/4. Moreover, $68 \%(34 / 50)$ of RCC patients belonged to T1a/b (34/50, $68 \%)$. In addition, $18 \%(9 / 50)$ of RCC patients belonged to T2 and only $14 \%$ (7/50) belonged to T3/4 (Table 2). 


\begin{tabular}{|l|l|l|l|l|}
\hline Variable & $\boldsymbol{\beta}$ & Wald & $\mathbf{P}$ & OR $(95 \%$ C.I. $)$ \\
\hline Unadjusted $^{\mathrm{a}}$ & 0.053 & 3.684 & 0.055 & $0.948(0.898,1.001)$ \\
\hline Adjusted $^{\mathrm{a}}$ & 0.055 & 3.905 & 0.048 & $0.946(0.896,0.999)$ \\
\hline
\end{tabular}

Table 3. Multivariable logistic regression analysis of correlation between RCC and serum 25(OH)D

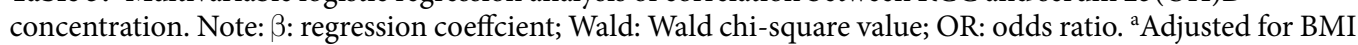
and age.

A

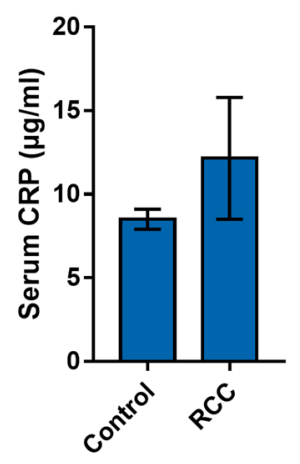

D

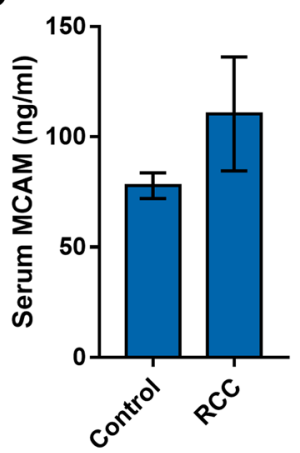

B

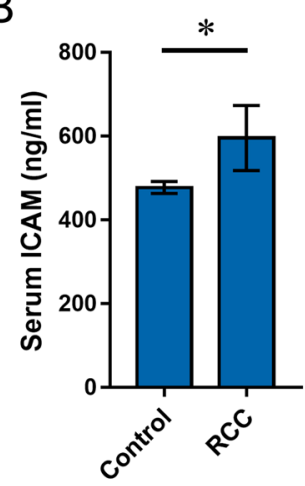

E

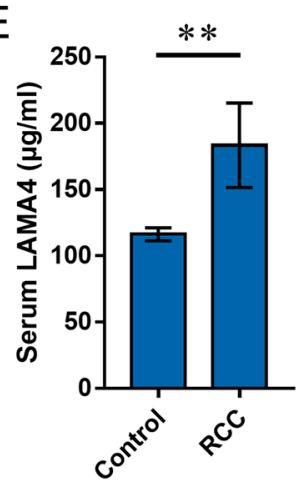

C

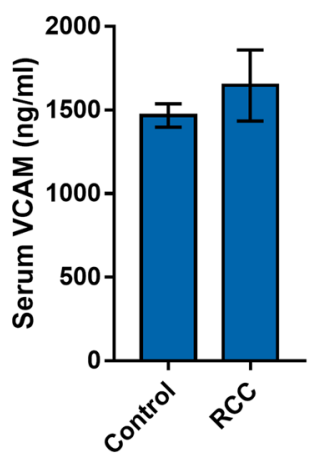

F

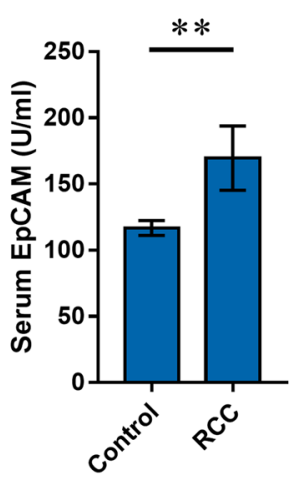

Figure 2. Serum CRP and adhesion molecule levels in RCC patients and controls. Serum CRP and adhesion molecules were measured using ELISA. Serum CRP, ICAM, VCAM, MCAM, LAMA4 and EpCAM levels were compared between RCC patients and controls. ( $\mathrm{N}=50$ for RCC patients; $\mathrm{N}=100$ for control subjects). (A) CRP; (B) ICAM; (C) VCAM; (D) MCAM; (E) LAMA4; (F) EpCAM. All data were expressed as means \pm S.E.M. $* P<0.05, * * P<0.01$.

Serum 25(OH)D is reduced in RCC patients. Serum 25(OH)D was analyzed among all subjects. As shown in Fig. 1A, 25(OH)D concentration was $20.73 \mathrm{ng} / \mathrm{ml}$ in RCC patients, significantly lower than $23.02 \mathrm{ng} /$ $\mathrm{ml}$ in controls. VDD is defined by most experts as a $25(\mathrm{OH}) \mathrm{D}$ level of less than $20 \mathrm{ng} / \mathrm{ml}$. A 25(OH)D level of greater than $20 \mathrm{ng} / \mathrm{ml}$ and less than $30 \mathrm{ng} / \mathrm{ml}$ is defined as vitamin D insufficiency (VDI), and $30 \mathrm{ng} / \mathrm{ml}$ or greater is defined as vitamin D sufficiency (VDS) ${ }^{32,44}$. We compared the vitamin D status between RCC patients and controls. We found that the proportion of subjects with VDD $(25(\mathrm{OH}) \mathrm{D}<20 \mathrm{ng} / \mathrm{ml})$, VDI $(20 \leq 25(\mathrm{OH})$ $\mathrm{D}<30 \mathrm{ng} / \mathrm{m})$ and VDS $(25(\mathrm{OH}) \mathrm{D} \geq 30 \mathrm{ng} / \mathrm{ml})$ in RCC patients were $44 \%, 48 \%$ and $8 \%$, respectively. The proportion of subjects with VDD, VDI and VDS in controls were $34 \%, 54 \%$ and $12 \%$, respectively. Although there is no significant difference, the proportion of RCC patients with VDD has an increasing trend. Accumulating data have demonstrated that overweight/obesity influences vitamin D status ${ }^{45,46}$. The present study found that BMI index of RCC patients was higher than that of controls. Thus, we further analyzed the association between RCC patients and serum $25(\mathrm{OH})$ by multivariable logistic regression, adjusting for BMI. The results are presented in Table 3 . As expected, a negative association between serum $25(\mathrm{OH}) \mathrm{D}$ and RCC was observed (adjusted OR: 0.946; $P<0.05$ ).

Nuclear VDR is reduced in cancerous tissues among RCC patients. Nuclear VDR levels were analyzed among RCC patients. As expected, nuclear VDR was reduced in cancerous tissue (Fig. 1B,C).

The levels of serum CRP and adhesion molecules are increased in RCC patients. Serum CRP was analyzed in RCC patients and controls. As shown in Fig. 2A, there was a rising trend on serum CRP level in RCC patients. Serum adhesion molecules were then analyzed in RCC patients and controls. Interestingly, serum 
A

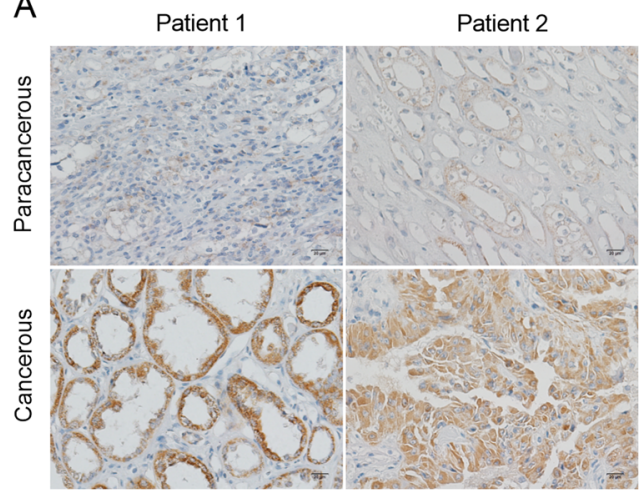

B

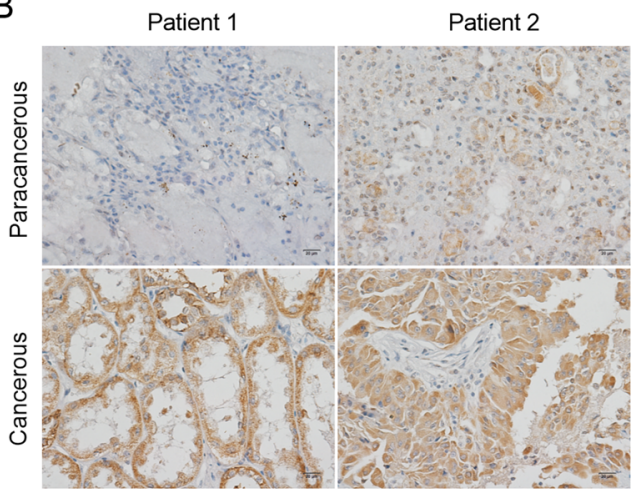

C

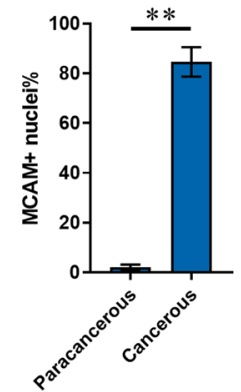

D

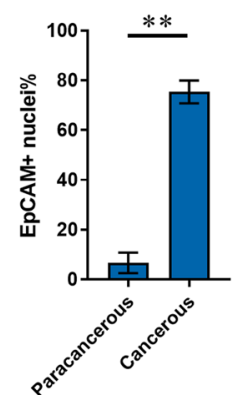

E

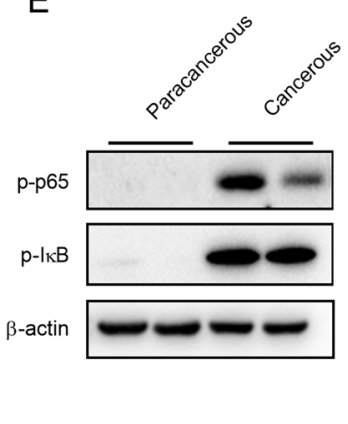

$\mathrm{F}$

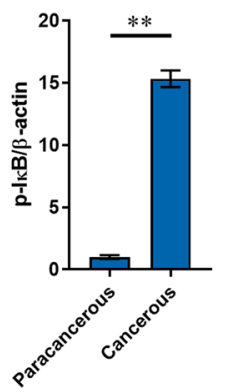

G

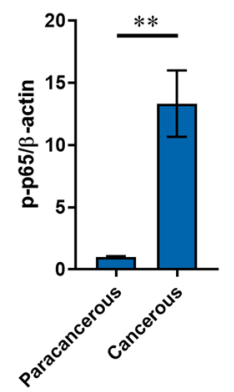

Figure 3. The distributions of adhesion molecules and activation of NF- $\kappa \mathrm{B}$ in cancerous and paracancerous tissues. (A-D) The distribution of MCAM and EpCAM in cancerous and paracancerous tissues was

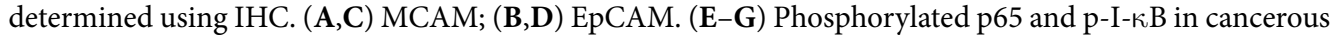
and paracancerous tissues was measured using Western blot. (E) A representative gel for p-p65 (upper panel),

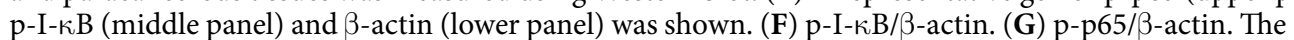
grouping of blots cropped from different gels of same samples. All data were expressed as means \pm S.E.M. $(\mathrm{N}=8) . * * \mathrm{P}<0.01$.

ICAM was elevated in RCC patients (Fig. 2B), whereas there was no difference on serum VCAM levels between two groups (Fig. 2C). As shown in Fig. 2D, there was a rising trend on serum MCAM. Laminin alpha 4 (LAMA4) is extracellular matrix interaction partner of $\mathrm{MCAM}^{22}$. As shown in Fig. 2E, the levels of serum LAMH4 were higher in RCC patients than those in controls. In addition, serum EpCAM was higher in RCC patients than that of controls (Fig. 2F). The distribution of MCAM and EpCAM, two adhesion molecules in cancerous tissues, was then determined among RCC patients. As expected, the expression of MCAM were much higher in cancerous tissue than that of paracancerous tissue (Fig. 3A,C). In addition, the expression of EpCAM in cancerous tissues was significantly higher than that of paracancerous tissue (Fig. 3B,D).

NF- $\kappa$ B is activated in cancerous tissues among RCC patients. Phosphorylated I- $\kappa$ B and NF- $\kappa$ B p65 were measured in cancerous tissue. As shown in Fig. 3E,F, the levels of p- I $\mathrm{B}$ were higher in cancerous tissue than in paracancerous tissue. The levels of p-p65 were accordingly higher in cancerous tissue than in paracancerous tissue (Fig. 3E,G).

Vitamin D status is reversely associated with serum CRP and adhesion molecules in RCC patients. Limited by the sample size, we defined patients with VDD (serum $25(\mathrm{OH}) \mathrm{D}<20 \mathrm{ng} / \mathrm{ml}$ ) as a low vitamin $\mathrm{D}$ status, while patients with $25(\mathrm{OH}) \mathrm{D} \geq 20 \mathrm{ng} / \mathrm{ml}$ is defined as a relatively high status. All RCC patients were divided into two groups according to serum 25(OH)D level: H-VitD ( $\geq 20 \mathrm{ng} / \mathrm{ml})$ or L-VitD $(<20 \mathrm{ng} / \mathrm{ml})$. Serum CRP level was compared between two groups. As shown in Fig. 4A, serum CRP level was significantly higher in RCC patients with L-VitD than those with H-VitD. The correlation between serum 25(OH)D and CRP levels was then analyzed among RCC patients and controls. As expected, serum $25(\mathrm{OH}) \mathrm{D}$ was not correlated with CRP among controls. Interestingly, serum $25(\mathrm{OH}) \mathrm{D}$ was reversely correlated with serum CRP among RCC patients (Table $4 ; r=-0.27, P<0.05$ ). Serum adhesion molecules were analyzed. As expected, the levels of all detected adhesion molecules were higher in RCC patients with L-VitD than those with H-VitD (Fig. 5B-F). The link between serum $25(\mathrm{OH}) \mathrm{D}$ and adhesion molecules was then analyzed. As expected, no link between serum $25(\mathrm{OH}) \mathrm{D}$ and all adhesion molecules was observed in controls (Table 4). Of interest, serum $25(\mathrm{OH}) \mathrm{D}$ was reversely correlated with serum ICAM $(r=-0.25, P<0.05)$, VCAM $(r=-0.23, P<0.05)$, MCAM $(r=-0.27$, $P<0.05)$, LAMA4 $(r=-0.23, P<0.05)$ and EpCAM $(r=-0.25, P<0.05)$ in RCC patients (Table 4$)$. 
A

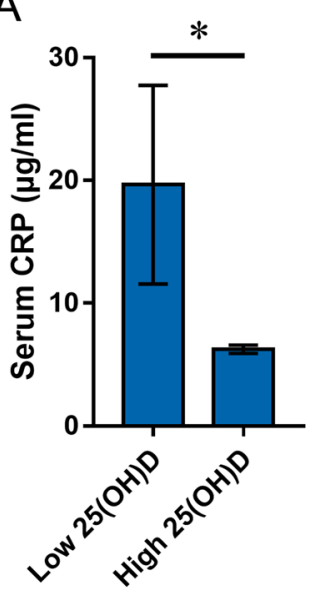

$\mathrm{D}$

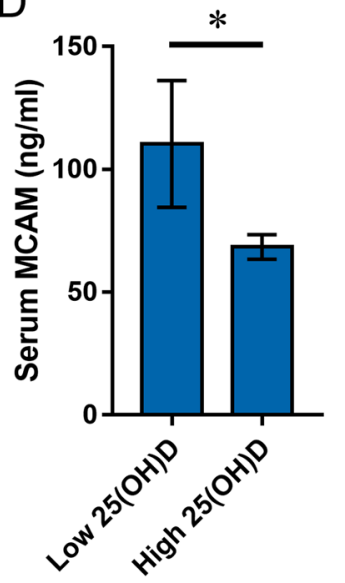

B

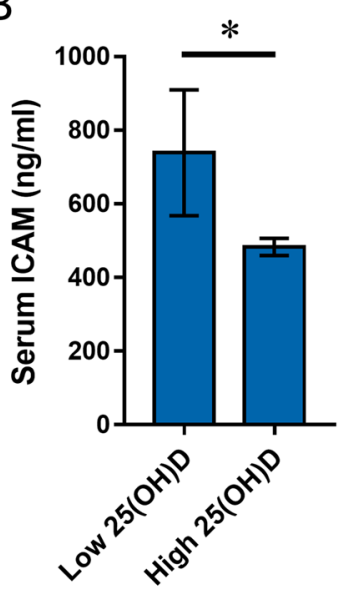

E

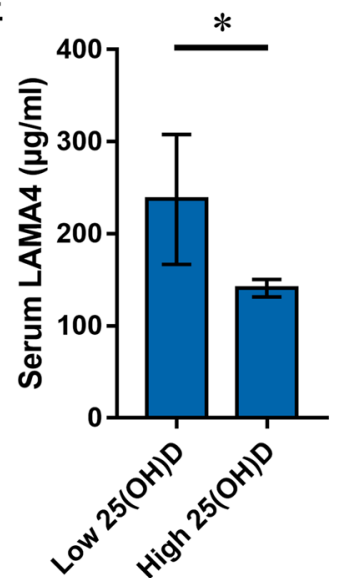

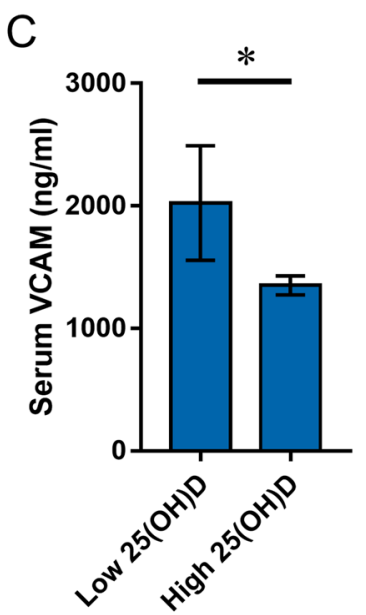

$\mathrm{F}$

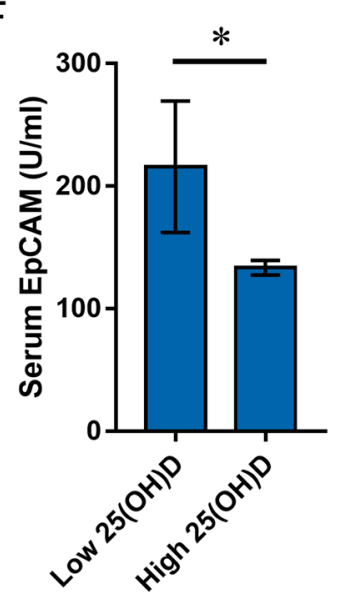

Figure 4. Low vitamin D status is associated with serum CRP and adhesion molecules in RCC patients. RCC patients were divided into two groups according to serum $25(\mathrm{OH}) \mathrm{D}$ level: $>20 \mathrm{ng} / \mathrm{ml}$ or $<20 \mathrm{ng} / \mathrm{ml}$. The levels of serum CRP and adhesion molecules were compared between two groups. (A) CRP; (B) ICAM; (C) VCAM; (D) MCAM; (E) LAMA4; (F) EpCAM. All data were expressed as means \pm S.E.M. $* \mathrm{P}<0.05$.

\begin{tabular}{|l|c|l|c|c|c|c|}
\hline & CRP & sICAM & sVCAM & MCAM & LAMA4 & EPCAM \\
\hline Control & 0.20 & -0.11 & 0.05 & 0.19 & 0.04 & 0.02 \\
\hline RCC & $-0.27^{\mathrm{a}}$ & $-0.25^{\mathrm{a}}$ & $-0.23^{\mathrm{a}}$ & $-0.27^{\mathrm{a}}$ & $-0.23^{\mathrm{a}}$ & $-0.25^{\mathrm{a}}$ \\
\hline
\end{tabular}

Table 4. Association between serum $25(\mathrm{OH}) \mathrm{D}$ and adhesion molecules. ${ }^{\mathrm{a}} \mathrm{P}<0.05$.

Vitamin D3 inhibits NF- $\kappa$ B activation and MCAM upregulation in RCC cells. To further explore the mechanism through which low vitamin D status upregulates expression of adhesion molecules among RCC patients, ACHN cells were pretreated with 1,25(OH)2D3, the active form of vitamin D3, and then stimulated with LPS to observe whether active vitamin D3 inhibits adhesion molecules in RCC cells. As expected, the levels of MCAM, LAMA4 and EpCAM were elevated in LPS-stimulated ACHN cells (Fig. 5C-E). Interestingly, pretreatment with 1,25(OH)2D3 suppressed LPS-evoked elevation of MCAM, LAMA4 and EpCAM in ACHN cells (Fig. 5C-E). The effects of pretreatment with $1,25(\mathrm{OH}) 2 \mathrm{D} 3$ on LPS-induced NF- $\kappa$ B activation were measured. As expected, the level of phosphorylated NF- $\kappa$ B was significantly elevated in LPS-stimulated ACHN cells (Fig. 5A,B). Interestingly, pretreatment with $1,25(\mathrm{OH}) 2 \mathrm{D} 3$ inhibited LPS-induced activation of NF- $\kappa \mathrm{B}$ in ACHN cells (Fig. 5A,B).

Vitamin D3 promotess integration between VDR and NF- $\kappa$ B p 65 subunit in RCC cells. The integration between VDR and NF- $\kappa$ B p65 subunit in RCC cells was measured by CoIP. As shown in Fig. 6, 1,25(OH)2D3 plus LPS elevated level of p65 in immunocomplexes precipitated by anti-VDR antibody. These results suggest an integration between VDR and NF- $\kappa$ B p 65 subunit in RCC cells. 
A

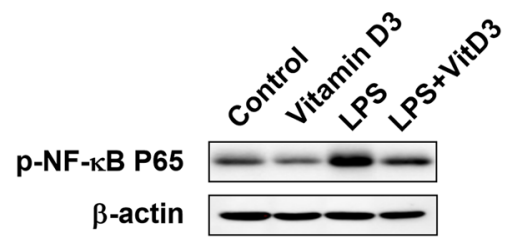

B

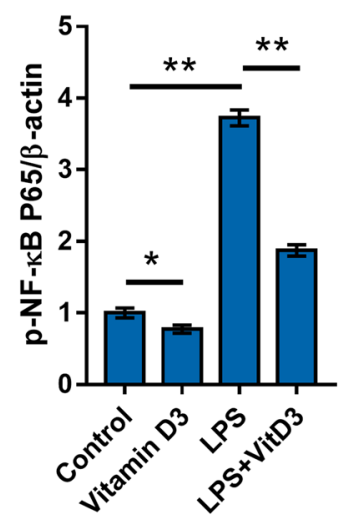

$E$

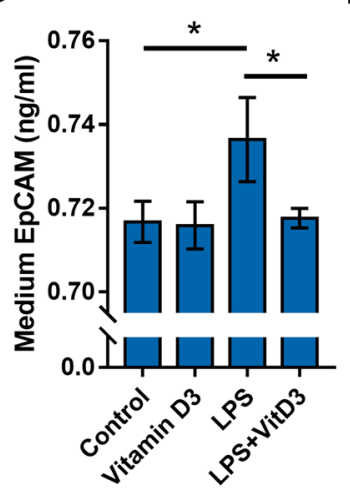

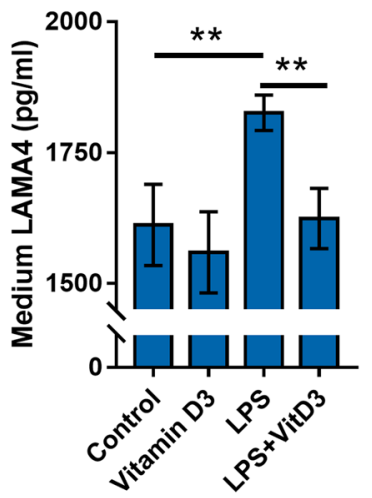

Figure 5. The effects of vitamin D3 on LPS-stimulated NF- $\kappa \mathrm{B}$ and adhesion molecules activation in RCC cells. $(\mathbf{A}, \mathbf{B})$ ACHN cells were pretreated with 1,25(OH)2D3, the active form of vitamin D3, and then stimulated with LPS for $6 \mathrm{~h}$. Phosphorylated p65 was measured using Western blot. (A) A representative gel for p-p65 (upper panel) and $\beta$-actin (lower panel) was shown. (B) p-p65/ $\beta$-actin. All experiments were repeated for six times. The grouping of blots cropped from different gels of same samples. All data were expressed as means \pm S.E.M. $(\mathrm{N}=6)$. $* * \mathrm{P}<0.01$. (C-E) ACHN cells were pretreated with 1,25(OH)2D3, the active form of vitamin D3, and then stimulated with LPS for $6 \mathrm{~h}$. The level of MCAM, LAMA4 and EpCAM in medium was measured using ELISA. (C) MCAM in medium; (D) LAMA4 in medium; (D) EpCAM in medium. All data were expressed as means \pm S.E.M. $(\mathrm{N}=8) . * * \mathrm{P}<0.01$.

A

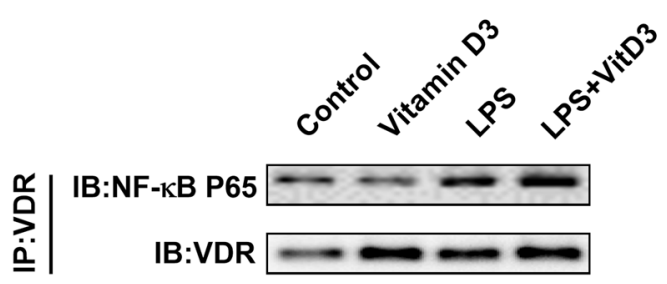

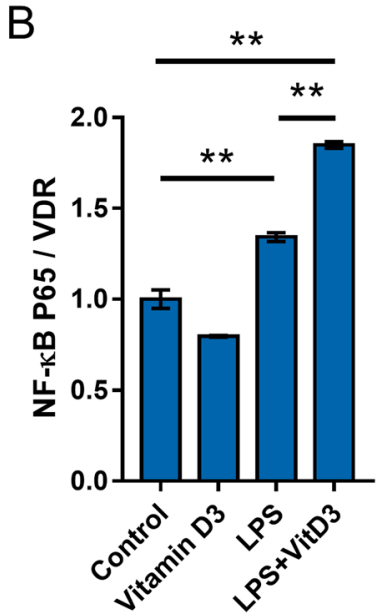

Figure 6. Vitamin D3 reinforces interaction between VDR and NF- $\kappa B$ p 65 subunit in RCC cells. ACHN cells were pretreated with $1,25(\mathrm{OH}) 2 \mathrm{D} 3$, the active form of vitamin $\mathrm{D} 3$, and then stimulated with LPS for $6 \mathrm{~h}$. The interaction between NF- $\kappa$ B p65 and VDR was detected using CoIP. All experiments were duplicated for four times. A representative gel for NF- $\kappa$ B p65 (upper panel) and VDR (lower panel) was shown. The grouping of blots cropped from different gels of same samples. All data were expressed as means \pm S.E.M. $(\mathrm{n}=4)$. $* * \mathrm{P}<0.01$ 


\section{Discussion}

Several epidemiological reports indicated that occupational ultraviolet exposure was negatively correlated with risk of RCC in different population ${ }^{47,48}$. A large prospective cohort study demonstrated that plasma $25(\mathrm{OH}) \mathrm{D}$ level was reversely associated with the incidence of RCC in men and women ${ }^{37}$. According to a report from the European Prospective Investigation into Cancer and Nutrition, circulating 25(OH)D was negatively associated with Odds Ratio of RCC after adjustment for confounding factors ${ }^{49}$. A recent study demonstrated that circulating $25(\mathrm{OH})$ $\mathrm{D}$ was positively associated with survival of kidney cancer $^{50}$. The present study analyzed the link of low vitamin D status with RCC risk. We found that circulating 25(OH)D in RCC patients was lower than that of controls. Multivariable logistic regression analysis indicated an inverse link between RCC and serum $25(\mathrm{OH}) \mathrm{D}$ after adjustment for confounding factors. These results suggest that low vitamin D status is linked with an increased RCC risk.

Indeed, all RCC patients recruited in this study are new cases, most of which belong to $\mathrm{T} 1 \mathrm{a} / \mathrm{b}(34 / 50,68 \%)$ and G1/2 (30/50, 60\%). Thus, additional research is necessary to analyze the correlation between serum $25(\mathrm{OH})$ $\mathrm{D}$ level and RCC severity in a large sample of population. The methods for determining serum $25(\mathrm{OH}) \mathrm{D}$ levels include HPLC, LC-MS/MS, RIA and ELISA. The LC-MS/MS is the most accurate method that can simultaneously measure serum $25(\mathrm{OH}) \mathrm{D} 2$ and $25(\mathrm{OH}) \mathrm{D} 3$. LC-MS/MS is usually used a gold standard. However, LC-MS/MS method is time-consuming. In addition, specimen pretreatment for LC-MS/MS is complicated and the results are greatly influenced by human factors. On the other hand, the RIA method is characterized by high sensitivity, specificity and precision, and low requirements for equipment and equipment. In addition, the RIA method has good consistency with LC-MS/MS method and is often used to detect serum 25(OH)D in a large sample of population $^{51,52}$. Thus, the RIA method is used to detect serum $25(\mathrm{OH}) \mathrm{D}$ in this study.

Numerous reports suggest that inflammation plays an important role in RCC metastases and progression ${ }^{53,54}$. CRP, a marker of inflammation, is an independent prognostic factor for overall survival of RCC patients ${ }^{8,55}$. An early report showed that an increase in preoperative CRP was linked with poor survival in patients with localized $\mathrm{RCC}^{56}$. According to a recent study, serum CRP level is a strong independent factor associated with survival of RCC patients treated with sunitinib ${ }^{57}$. This study analyzed the link between $25(\mathrm{OH}) \mathrm{D}$ and CRP in RCC patients. We found that serum CRP in RCC patients with L-VitD was higher than those with H-VitD. Further analysis found that serum CRP level was reversely correlated with serum 25(OH)D level among RCC patients. The study indicates that low vitamin D status is linked with increased serum CRP among RCC patients.

Accumulating data have demonstrated that adhesion molecules are prognostic molecular markers in RCC patients. Two early studies showed that patients with short survival or advanced RCC had higher levels of serum ICAM-1 than low-grade and/or low-stage RCC patients ${ }^{58,59}$. Another report indicated that VCAM-1, commonly overexpressed in RCC, was involved in tumor immune evasion ${ }^{60}$. According to a recent study, MCAM and its extracellular matrix interaction partner LAMA4, highly expressed in locally advanced tumors as well as secondary metastases, were predictive markers for poor RCC prognosis ${ }^{22}$. The present study showed that serum ICAM, LAMA4 and EpCAM were higher in RCC patients than in controls. Importantly, MCAM and EpCAM were highly expressed only in cancerous tissue but not in paracancerous tissue. Further observation found that the levels of all detected adhesion molecules were higher in RCC patients with L-VitD than those with L-VitD. These results suggest that low vitamin D status is associated with increased expression of adhesion molecules among RCC patients.

The mechanism through which VDD upregulates expression of adhesion molecules among RCC patients remains obscure. An in vitro study demonstrated that active VitD3 downregulated expression of ICAM-1 and VCAM-1 in endothelial cells through suppressing NF- $\kappa B$ activation ${ }^{61}$. According to an in vivo report, pretreatment with VitD3 attenuated LPS-induced upregulation of renal ICAM-1 and VCAM-1 by inhibiting activation of NF- $\kappa B$ in the kidneys ${ }^{62}$. In the present study, we found that nuclear VDR was low in cancerous tissue. By contrary, renal NF- $\kappa B$ was activated only in cancerous but not in paracancerous tissue. Correspondingly, renal adhesion molecules were highly expressed only in cancerous tissue but not in paracancerous tissue. The in vitro experiments found that VitD3 blocked activation of NF- $\mathrm{KB}$ and suppressed upregulation of adhesion molecules in RCC cells. Moreover, VitD3 suppressed NF- $\kappa B$ through promoting the integration between VDR and NF- $\kappa B$ p65 in RCC cells, which provides a mechanistic explanation for linking VDD, low VDR and increased expression of adhesion molecules in RCC patients.

The present study placed emphasis on analyzing the association of low vitamin D status with serum CRP and adhesion molecules among RCC patients. We demonstrated that there was a link among low vitamin D status, cancerous NF- $\kappa$ B activation and increased expression of adhesion molecules in RCC patients. However, the present study is observational. The findings herein described are not concretely able to demonstrate a causal association between both CRP and adhesion molecules and the prognosis of RCC patients with low vitamin D status. Several studies have demonstrated that serum calcium level is a factor of prognosis ${ }^{62}$. Thus, further studies are required to identify a causal association between both CRP and adhesion molecules and the prognosis of RCC patients with low vitamin D status. In addition, an in vivo experiment may be needed to measure the effects of supplementation with VitD3 on serum CRP and adhesion molecules as well as NF- $\kappa B$ signaling in RCC animal model.

In summary, the present study analyzed the association of low vitamin D status with serum CRP and adhesion molecules in RCC patients. We showed that serum 25(OH)D level was reduced among RCC patients. By contrast, the expression of renal adhesion molecules was upregulated among RCC patients. Moreover, vitamin D status was reversely correlated with serum CRP and adhesion molecules among RCC patients. We observed that NF- $\kappa \mathrm{B}$ in cancerous tissue was activated among RCC patients. The in vitro experiments found that active VitD3 suppressed NF- $\kappa$ B activation and adhesion molecules through promoting integration between VDR and NF- $\kappa$ B p65 in RCC cells. Our results suggest a link among low vitamin D status, local inflammation and increased expression of adhesion molecules in RCC patients.

Received: 23 April 2019; Accepted: 30 October 2019;

Published online: 13 November 2019 


\section{References}

1. Ljungberg, B. et al. The Epidemiology of Renal Cell Carcinoma. European Urology 60, 615-621, https://doi.org/10.1016/j. eururo.2011.06.049 (2011).

2. Znaor, A., Lortet-Tieulent, J., Laversanne, M., Jemal, A. \& Bray, F. International Variations and Trends in Renal Cell Carcinoma Incidence and Mortality. European Urology 67, 519-530, https://doi.org/10.1016/j.eururo.2014.10.002 (2015).

3. Zucchetto, A. et al. History of treated hypertension and diabetes mellitus and risk of renal cell cancer. Ann Oncol 18, 596-600, https://doi.org/10.1093/annonc/mdl438 (2007).

4. Choi, Y. et al. Body mass index and survival in patients with renal cell carcinoma: a clinical-based cohort and meta-analysis. Int $J$ Cancer 132, 625-634, https://doi.org/10.1002/ijc.27639 (2013).

5. Deckers, I. A. et al. Long-term dietary sodium, potassium and fluid intake; exploring potential novel risk factors for renal cell cancer in the Netherlands Cohort Study on diet and cancer. Br J Cancer 110, 797-801, https://doi.org/10.1038/bjc.2013.771 (2014).

6. Cumberbatch, M. G., Rota, M., Catto, J. W. F. \& La Vecchia, C. The Role of Tobacco Smoke in Bladder and Kidney Carcinogenesis: A Comparison of Exposures and Meta-analysis of Incidence and Mortality Risks. European Urology 70, 458-466, https://doi. org/10.1016/j.eururo.2015.06.042 (2016).

7. Zhu, J. et al. Glycemic index, glycemic load and carbohydrate intake in association with risk of renal cell carcinoma. Carcinogenesis 38, 1129-1135, https://doi.org/10.1093/carcin/bgx083 (2017).

8. Zhou, L. et al. Prognostic Role of C-Reactive Protein In Urological Cancers: A Meta-Analysis. Scientific Reports 5, 12733, https://doi. org/10.1038/srep12733, https://www.nature.com/articles/srep12733\#supplementary-information (2015).

9. Dalpiaz, O. et al. Critical evaluation of the potential prognostic value of the pretreatment-derived neutrophil-lymphocyte ratio under consideration of C-reactive protein levels in clear cell renal cell carcinoma. British journal of cancer 116, 85-90 (2017).

10. Wang, Z. et al. C-reactive protein is a predictor of prognosis in renal cell carcinoma patients receiving tyrosine kinase inhibitors: A meta-analysis. Clinica chimica acta international journal of clinical chemistry 475, 178-187 (2017).

11. Sun, K. H. et al. TNF-alpha augments CXCR2 and CXCR3 to promote progression of renal cell carcinoma. J Cell Mol Med 20, 2020-2028, https://doi.org/10.1111/jcmm.12890 (2016).

12. Usami, Y. et al. Intercellular adhesion molecule-1 (ICAM-1) expression correlates with oral cancer progression and induces macrophage/cancer cell adhesion. Int J Cancer 133, 568-578, https://doi.org/10.1002/ijc.28066 (2013).

13. Zheng, Y., Yang, W., Aldape, K., He, J. \& Lu, Z. Epidermal growth factor (EGF)-enhanced vascular cell adhesion molecule-1 (VCAM1) expression promotes macrophage and glioblastoma cell interaction and tumor cell invasion. J. Biol. Chem. 288, 31488-31495 (2013).

14. Sechler, M., Parrish, J. K., Birks, D. K. \& Jedlicka, P. The histone demethylase KDM3A, and its downstream target MCAM, promote Ewing Sarcoma cell migration and metastasis. Oncogene 36, 4150-4160 (2017).

15. Liang, K. H. et al. Extracellular domain of EpCAM enhances tumor progression through EGFR signaling in colon cancer cells. Cancer letters 433, 165-175 (2018).

16. Zabouo, G. et al. CD146 expression is associated with a poor prognosis in human breast tumors and with enhanced motility in breast cancer cell lines. Breast Cancer Res. 11, R1 (2009).

17. Bryan, R. T. et al. Urinary EpCAM in urothelial bladder cancer patients: characterisation and evaluation of biomarker potential. $\mathrm{Br}$ J Cancer 110, 679-685, https://doi.org/10.1038/bjc.2013.744 (2014).

18. Goossens-Beumer, I. J. et al. Clinical prognostic value of combined analysis of Aldh1, Survivin, and EpCAM expression in colorectal cancer. Br J Cancer 110, 2935-2944, https://doi.org/10.1038/bjc.2014.226 (2014).

19. Ilie, M. et al. Clinical value of circulating endothelial cells and of soluble CD146 levels in patients undergoing surgery for non-small cell lung cancer. Br J Cancer 110, 1236-1243, https://doi.org/10.1038/bjc.2014.11 (2014).

20. Wang, J. et al. The membrane protein melanoma cell adhesion molecule (MCAM) is a novel tumor marker that stimulates tumorigenesis in hepatocellular carcinoma. Oncogene 34,5781, https://doi.org/10.1038/onc.2015.36, https://www.nature.com/ articles/onc201536\#supplementary-information (2015).

21. Nodomi, S. et al. CD146 is a novel marker for highly tumorigenic cells and a potential therapeutic target in malignant rhabdoid tumor. Oncogene 35, 5317-5327, https://doi.org/10.1038/onc.2016.72 (2016).

22. Wragg, J. W. et al. MCAM and LAMA4 Are Highly Enriched in Tumor Blood Vessels of Renal Cell Carcinoma and Predict Patient Outcome. Cancer Res 76, 2314-2326, https://doi.org/10.1158/0008-5472.CAN-15-1364 (2016).

23. Noh, C.-K. et al. EpCAM as a Predictive Marker of Tumor Recurrence and Survival in Patients Who Underwent Surgical Resection for Hepatocellular Carcinoma. Anticancer Research 38, 4101-4109, https://doi.org/10.21873/anticanres.12700 (2018).

24. Zhou, L. \& Zhu, Y. The EpCAM overexpression is associated with clinicopathological significance and prognosis in hepatocellular carcinoma patients: A systematic review and meta-analysis. International journal of surgery 56, 274-280 (2018).

25. Veldurthy, V. et al. Vitamin D, calcium homeostasis and aging. Bone Res 4, 16041, https://doi.org/10.1038/boneres.2016.41 (2016).

26. Feldman, D., Krishnan, A. V., Swami, S., Giovannucci, E. \& Feldman, B. J. The role of vitamin D in reducing cancer risk and progression. Nature Reviews Cancer 14, 342, https://doi.org/10.1038/nrc3691, https://www.nature.com/articles/ nrc3691\#supplementary-information (2014).

27. Colotta, F., Jansson, B. \& Bonelli, F. Modulation of inflammatory and immune responses by vitamin D. J Autoimmun 85, 78-97, https://doi.org/10.1016/j.jaut.2017.07.007 (2017).

28. Welsh, J. Vitamin D and breast cancer: Past and present. The Journal of Steroid Biochemistry and Molecular Biology 177, 15-20, https://doi.org/10.1016/j.jsbmb.2017.07.025 (2018).

29. Ali, A., Cui, X. \& Eyles, D. Developmental vitamin D deficiency and autism: Putative pathogenic mechanisms. The Journal of Steroid Biochemistry and Molecular Biology 175, 108-118, https://doi.org/10.1016/j.jsbmb.2016.12.018 (2018).

30. Xu, S. et al. Vitamin D3 pretreatment alleviates renal oxidative stress in lipopolysaccharide-induced acute kidney injury. The Journal of Steroid Biochemistry and Molecular Biology 152, 133-141, https://doi.org/10.1016/j.jsbmb.2015.05.009 (2015).

31. Powe, C. E. et al. Vitamin D-binding protein and vitamin D status of black Americans and white Americans. N Engl J Med 369, 1991-2000, https://doi.org/10.1056/NEJMoa1306357 (2013).

32. Chen, Y. H. et al. Maternal vitamin D deficiency during pregnancy elevates the risks of small for gestational age and low birth weight infants in Chinese population. J Clin Endocrinol Metab 100, 1912-1919, https://doi.org/10.1210/jc.2014-4407 (2015).

33. Murphy, A. B. et al. Vitamin D deficiency predicts prostate biopsy outcomes. Clin Cancer Res 20, 2289-2299, https://doi. org/10.1158/1078-0432.CCR-13-3085 (2014).

34. Kelly, J. L. et al. Low Serum Vitamin D Levels Are Associated With Inferior Survival in Follicular Lymphoma: A Prospective Evaluation in SWOG and LYSA Studies. J Clin Oncol 33, 1482-1490, https://doi.org/10.1200/JCO.2014.57.5092 (2015).

35. Mondul, A. M., Weinstein, S. J., Layne, T. M. \& Albanes, D. Vitamin D and Cancer Risk and Mortality: State of the Science, Gaps, and Challenges. Epidemiol Rev 39, 28-48, https://doi.org/10.1093/epirev/mxx005 (2017).

36. de Sousa Almeida-Filho, B. et al. Vitamin D deficiency is associated with poor breast cancer prognostic features in postmenopausal women. The Journal of Steroid Biochemistry and Molecular Biology 174, 284-289, https://doi.org/10.1016/j.jsbmb.2017.10.009 (2017).

37. Joh, H. K., Giovannucci, E. L., Bertrand, K. A., Lim, S. \& Cho, E. Predicted plasma 25-hydroxyvitamin D and risk of renal cell cancer. J Natl Cancer Inst 105, 726-732, https://doi.org/10.1093/jnci/djt082 (2013). 
38. Jones, G., Prosser, D. E. \& Kaufmann, M. Cytochrome P450-mediated metabolism of vitamin D. J Lipid Res 55, 13-31, https://doi. org/10.1194/jlr.R031534 (2014).

39. Christakos, S., Dhawan, P., Verstuyf, A., Verlinden, L. \& Carmeliet, G. Vitamin D: Metabolism, Molecular Mechanism of Action, and Pleiotropic Effects. Physiol Rev 96, 365-408, https://doi.org/10.1152/physrev.00014.2015 (2016).

40. Blomberg Jensen, M. et al. Expression of the vitamin D receptor, 25 -hydroxylases, $1 \alpha$-hydroxylase and 24-hydroxylase in the human kidney and renal clear cell cancer. The Journal of Steroid Biochemistry and Molecular Biology 121, 376-382, https://doi.org/10.1016/j. jsbmb.2010.03.069 (2010).

41. Edge, S. \& Compton, C. The American Joint Committee on Cancer: the 7th edition of the AJCC cancer staging manual and the future of TNM. Ann. Surg. Oncol. 17, 1471-1474 (2010).

42. Fuhrman, S., Lasky, L. \& Limas, C. Prognostic significance of morphologic parameters in renal cell carcinoma. Am. J. Surg. Pathol. 6, 655-663 (1982).

43. Song, J. et al. The correlation between low vitamin D status and renal interleukin-6/STAT3 hyper-activation in patients with clear cell renal cell carcinoma. Steroids 150, 108445, https://doi.org/10.1016/j.steroids.2019.108445 (2019).

44. Holick, M. Vitamin D deficiency. N. Engl. J. Med. 357, 266-281 (2007).

45. Vimaleswaran, K. et al. Causal relationship between obesity and vitamin D status: bi-directional Mendelian randomization analysis of multiple cohorts. PLoS Med. 10, e1001383 (2013).

46. Afzal, S., Brøndum-Jacobsen, P., Bojesen, S. \& Nordestgaard, B. Vitamin D concentration, obesity, and risk of diabetes: a mendelian randomisation study. Lancet Diabetes Endocrinol 2, 298-306 (2014).

47. Karami, S. et al. Occupational sunlight exposure and risk of renal cell carcinoma. Cancer 116, 2001-2010, https://doi.org/10.1002/ cncr.24939 (2010).

48. Karami, S. et al. A case-control study of occupational sunlight exposure and renal cancer risk. Int J Cancer 138, 1626-1633, https:// doi.org/10.1002/ijc.29902 (2016).

49. Muller, D. C. et al. Circulating 25-hydroxyvitamin D3 in relation to renal cell carcinoma incidence and survival in the EPIC cohort. Am J Epidemiol 180, 810-820, https://doi.org/10.1093/aje/kwu204 (2014).

50. Muller, D. C. et al. Circulating 25-hydroxyvitamin D3 and survival after diagnosis with kidney cancer. Cancer epidemiology, biomarkers prevention 24, 1277-1281 (2015).

51. Farrell, C. et al. State-of-the-art vitamin D assays: a comparison of automated immunoassays with liquid chromatography-tandem mass spectrometry methods. Clin. Chem. 58, 531-542 (2012).

52. Janssen, M. et al. Multicenter comparison study of current methods to measure 25 -hydroxyvitamin D in serum. Steroids 77 , 1366-1372 (2012).

53. Fox, P. et al. Markers of systemic inflammation predict survival in patients with advanced renal cell cancer. Br J Cancer 109, 147-153, https://doi.org/10.1038/bjc.2013.300 (2013).

54. Fu, Q. et al. Prognostic value of interleukin-6 and interleukin-6 receptor in organ-confined clear-cell renal cell carcinoma: a 5-year conditional cancer-specific survival analysis. Br J Cancer 113, 1581-1589, https://doi.org/10.1038/bjc.2015.379 (2015).

55. Jagdev, S. P. et al. Improving the accuracy of pre-operative survival prediction in renal cell carcinoma with C-reactive protein. $\mathrm{Br} \mathrm{J}$ Cancer 103, 1649-1656, https://doi.org/10.1038/sj.bjc.6605973 (2010).

56. Komai, Y., Saito, K., Sakai, K. \& Morimoto, S. Increased preoperative serum C-reactive protein level predicts a poor prognosis in patients with localized renal cell carcinoma. BJU Int 99, 77-80, https://doi.org/10.1111/j.1464-410X.2006.06497.x (2007).

57. Beuselinck, B. et al. Prognostic impact of baseline serum C-reactive protein in patients with metastatic renal cell carcinoma (RCC) treated with sunitinib. BJU Int 114, 81-89, https://doi.org/10.1111/bju.12494 (2014).

58. Heicappell, R., Podlinski, J., Buszello, H. \& Ackermann, R. Cell surface expression and serum levels of intercellular adhesion molecule-1 in renal cell carcinoma. Urol. Res. 22, 9-15 (1994).

59. Kallio, J., Tammela, T., Marttinen, A. \& Kellokumpu-Lehtinen, P. Soluble immunological parameters and early prognosis of renal cell cancer patients. J. Exp. Clin. Cancer Res. 20, 523-528 (2001).

60. Wu, T. C. The role of vascular cell adhesion molecule-1 in tumor immune evasion. Cancer Res 67, 6003-6006, https://doi. org/10.1158/0008-5472.CAN-07-1543 (2007).

61. Lee, A. S. et al. Paricalcitol attenuates lipopolysaccharide-induced myocardial inflammation by regulating the NF-kappaB signaling pathway. Int J Mol Med 37, 1023-1029, https://doi.org/10.3892/ijmm.2016.2516 (2016).

62. Xu, S. et al. Vitamin D3 pretreatment regulates renal inflammatory responses during lipopolysaccharide-induced acute kidney injury. Scientific Reports 5(1) (2016).

\section{Acknowledgements}

This research was funded by a key project of the National Natural Science Foundation of China (no. 81630084). The authors would like to thank Dr. Mi-Zhen Xia and Prof. Yuan-Hua Chen for their excellent technical support.

\section{Author contributions}

Conceptualization, Shen Xu, De-Xin Yu, De-Xiang Xu and Guo-Ping Sun; Data curation, Shen Xu and Zhi-Hui Zhang; Formal analysis, Shen Xu and Zhi-Hui Zhang; Investigation, Shen Xu and Lin Fu; Methodology, Shen Xu, Lin Fu and Lan Gao; Resources, Jin Song and Dong-Dong Xie; Supervision, De-Xiang Xu and Guo-Ping Sun; Writing - original draft, Shen Xu; Writing - review \& editing, De-Xiang Xu.

\section{Competing interests}

The authors declare no competing interests.

\section{Additional information}

Correspondence and requests for materials should be addressed to D.-X.X. or G.-P.S.

Reprints and permissions information is available at www.nature.com/reprints.

Publisher's note Springer Nature remains neutral with regard to jurisdictional claims in published maps and institutional affiliations. 
(c) (i) Open Access This article is licensed under a Creative Commons Attribution 4.0 International License, which permits use, sharing, adaptation, distribution and reproduction in any medium or format, as long as you give appropriate credit to the original author(s) and the source, provide a link to the Creative Commons license, and indicate if changes were made. The images or other third party material in this article are included in the article's Creative Commons license, unless indicated otherwise in a credit line to the material. If material is not included in the article's Creative Commons license and your intended use is not permitted by statutory regulation or exceeds the permitted use, you will need to obtain permission directly from the copyright holder. To view a copy of this license, visit http://creativecommons.org/licenses/by/4.0/.

(C) The Author(s) 2019 